\title{
Teacher development in ICT: Vision and implementation
}

\author{
Iliana Nikolova \\ Department of Information Technologies, Faculty of Mathematics and Informatics, \\ University of Sofia, FMI-KIT, P.B. 48, 5, James Bouchier, Sofia 1164, Bulgaria. \\ iliana@fmi.uni-sofia.bg
}

\begin{abstract}
The paper presents the philosophy and practices of the Department of Information Technologies and the Teacher Training Center at the Faculty of Mathematics and Informatics, University of Sofia, related to teacher development in Information and Communication Technologies. The conceptual framework for teacher development calls for an integrated approach to the problem: the various forms for teacher training and continuing support are combined with activities, aiming at influencing the system in which the teachers work. The approach embeds "teachers as change agents" paradigm and aims at creating sustainable links, both vertical (between the research and training units and teachers) and horizontal (among teachers themselves), finally building an informal professional society of researchers, trainers and teachers who communicate, collaborate and share. The teacher development processes are initiated in a university environment in which research, development and teaching are closely interrelated. This creates added-value opportunities and experiences for the participating teachers. The scope of activities includes workshops and seminars for teachers; strategy and curriculum development in ICT; educational software and learning materials development; carrying out educational and researches projects; building WWW support environment for teachers.
\end{abstract}

Keywords: Flexible learning, Internet, Logo, multimedia
The Information and Communications Technologies will have a substantial effect on what we do in schools just as the advent of the pen and paper did in the past.
Seymour Papert

The original version of this chapter was revised: The copyright line was incorrect. This has been corrected. The Erratum to this chapter is available at DOI: 10.1007/978-0-387-35403-3_29 


\section{INTRODUCTION}

One of the greatest achievements of this century is the remarkable development in the area of ICT. The rapid technological changes affect many aspects of our lives, including the way we learn. The school of tomorrow will embed learning in technology rich educational environments. This will be natural for the new generation of children for whom the technology is already part of their everyday life. How will teacher's role evolve? How will schools cope with the change? What can be done today to prepare for tomorrow? Such questions seek their answers at the threshold of the new millenium.

This paper presents the philosophy and practices of the Department of Information Technologies (DIT) and the Teacher Training Center (TTC) at the Faculty of Mathematics and Informatics, University of Sofia, related to teacher development in Information and Communication Technologies (ICT). First the profiles of DIT and TTC are briefly outlined. Then a vision for the role of the teacher in the future is presented. Next the milestones of the conceptual framework for teacher development are discussed and current problems are identified. The ideas are illustrated by a number of examples, some including WWW solutions for teacher support. Finally, implications for future teacher education in Bulgaria and other countries are drawn.

\section{THE DEPARTMENT OF IT AND THE TEACHER TRAINING CENTRE (TTC)}

The Department of Information Technologies (DIT, http://wwwit.fmi.uni-sofia.bg) was established in 1993 as an ancestor of the Educational Computing Systems Laboratory founded in 1984. The Department's activities involve teaching, research and development in the field of ICT and their applications in education. DIT is responsible for teaching informatics and computer education topics in a B.Sc. program, where teachers in mathematics and informatics are prepared. It offers also two M.Sc. programs: "Information and Communication Technologies" and "Artificial Intelligence". In 1994 a functional unit - Teacher Training Center - was established to deal with in-service teacher training for the integration of ICT in schools. The Center is not a separate administrative unit with own staff and budget - its activities are carried out by the staff of the Department and by external collaborators, including teachers. 


\section{A VISION FOR TEACHER DEVELOPMENT}

\subsection{The role of the teacher in the future}

The teacher will be teaching in an Information Society, i.e. in an information and technology rich environment. The way people learn will change and this change will be accelerated by the "kidpower" (Papert, 1999): the computer oriented generation of children now entering the educational system. ICT will play a substantial role in this change by offering new educational media and provoking new educational paradigms. Teachers have to adapt to this change, even more - to act as "change agents" and help shaping new school cultures. They should be fluent users of ICT themselves and capable to employ ICT to empower students' learning, but also recognise uses of ICT, which can disempower learning.

The variety in the forms of learning will increase. It is very likely that the school of the future will be differently organised and the traditional classroom-based learning with fixed timetables will decline. The curriculum will be restructured to support more resource-based and project-oriented learning. The role of the teacher will evolve into navigating learning in technology rich educational environments and into designing learning environments that allow more flexible learning, mediated by technology.

\subsection{Conceptual framework for teacher development}

At Tele-Teaching'98 Niki Davis said: "Preparing teachers is perceived as the main critical success factor in deploying ICT in education. Teacher trainers and teachers have key roles to play. They can spread the benefits of the Information Society through their enthusiasm and by the innovative new work techniques, which many are adopting. Often these changes to working practice are occurring by teacher trainers altering the processes and organization within their institutions."

\subsubsection{Goals, methods, tools and roles}

Goals. Teacher development should contribute to building a coherent and consistent professional culture for using ICT in teachers' practices. ICT should become a natural component of school everyday life. Teachers need to be able to recognise powerful ICT uses for learning purposes and to design appropriate ICT solutions for practical cases. To keep up-to-date they have to learn to learn continuously (considering also tele-learning options). 
They need to develop a positive attitude and culture for professional collaboration.

Methods. To be effective and to build transferable skills, teacher education and training has to be based on constructionist learning principles (Paper, 1999) and to embed active, experiential learning. The teacher development processes have to be supported by rich environments (Nikolova, 1999), in terms of educational, technological and human resources. These environments should offer powerful ideas, methods, tools, technologies and examples of good practices. Teachers' have to be involved in multifaceted activities, which give them different kinds of experiences, and create opportunities to develop various competencies. In this way valuable experience is gained which allows such teachers to serve as change agents in their school environment. Further (on-the-job) support to teachers is important for the success of the school innovation processes. Internet and Intranets can play an important role in designing such support solutions.

Tools. Traditionally, DIT values interactive software environments for learning which support exploration and creative expression (i.e., embed some sort of language) and allow teachers to develop their own applications. Such environments are a powerful context for constructionist learning. Examples of such environments are Comenius Logo, Geomland and $\mathrm{MATCH}$, mentioned further in this paper.

Roles. This conceptual framework is based on the active learner assumption. The learner (in this case, the teacher) is a citizen of the cyberspace with access to on-line information, learning resources and communication facilities. The teacher trainer is a facilitator, a navigator of the learning process, consultant in the selection and utilisation of the learning resources. The teacher development processes vary from formal, fixed in time and space instructional sessions to informal, self-initiated, flexible in time and place learning, supported by off and on-line resources and by collaboration with peers and communication with experts.

\subsubsection{Key ideas (from an implementation perspective)}

There are three main target groups to whom DIT's and TTC's deliver training in ICT: pre-service teachers, master students in ICT and AI, and inservice teachers. Establishing links among these three groups in order to facilitate mutual enrichment and create synergy effects is one of the key ideas in our approach to teacher development. It is realized by forming small teams, involving people from the three groups and consultants from the 
Department. These teams work on different tasks, e.g. curriculum development, project work, development of software applications and teaching and learning materials, building WWW support environments, testing research outcomes in school settings. Examples of such cooperative work are VALUE, MATCH, development of ICT curriculum, NETLogo Teachers' Course (see the paragraph Examples from practice).

Another key idea is to make the teacher training more flexible and multifaceted in terms of methods and forms. The traditional classroom based teaching is minimized in favor to more hands-on experience, seminars, discussions, individual and small group project work, individual consultations with teachers and schools, and, where possible, involvement of teachers in real research and development projects carried out at DIT.

The third key idea is to build rich environments for learning and continuous support to teachers. After the formal period of training is over, i.e. when the teachers return to their school environment, they often need advice and further support. We try to help in different ways: (a) by building full range of support materials around the educational software environments, which we consider appropriate for school use (examples are Comenius Logo, Geomland, MATCh); (b) by building WWW support environments for teachers (examples are VALUE, GEOMLAND and School Resource Bank - see "Examples from practice"); (c) by being available for e-mail support, telephone and face-to-face consultations.

The fourth key idea is to facilitate the change - the integration of ICT and accommodation of teachers and schools to it - by influencing the system itself. At EUROLOGO'99 Seymour Papert said: "Educational change is possible, but the educational system has to be allowed to evolve itself, rather than attempting to impose changes on it." To achieve this, we act both "topdown" and "bottom-up":

(a) Collaboration is established with educational institutions: the Ministry of education, educational institutes, regional ICT -co-ordinators, school masters. Examples are: participation of leading researchers, teacher trainers and teachers in the development of the National Strategy for integration of ICT in schools (Eskenazi et al, 1998) and in curriculum development at national level (see "Curriculum development" in the "Examples from Practice"); formal and informal discussions with local educational authorities and school administration.

(b) The "teachers as change agents"-paradigm is employed: Opportunities are provided for motivated teachers to get deeper involved in various kinds of activities at the Department. Thus they can feel the spirit, to benefit from the collaboration with staff, affiliated members, and other teachers, to discuss extensively "the message" of our concept for integration of ICT in schools and to practice it in different ways. When "well armed" with vision 
and experience, these teachers are "implemented" in schools, keeping close contact with us, bringing innovative practices to the school and influencing colleagues and school administration.

The fifth key idea is to build an informal professional society of researchers, trainers and teachers who communicate, collaborate and share. The aim is to establish sustainable links, both vertical (between the research and training units and teachers) and horizontal (among teachers themselves). Throughout the teacher development process we are building a "human network" (supported by an electronic database) and encourage peer support and collaboration among its members. Web support tools are also employed for this purpose (examples are VALUE, GEOMLAND, NETLogo Educational Site).

The sixth key idea is to facilitate international co-operation at teacher and school level and help establish direct channels for communication via Internet. This is done by organising international events and enabling teachers participate in them (one recent example is EUROLOGO99 hosted by the Department), by helping teachers establish partnerships and start projects, by involving teachers in development, evaluation and validation activities within DIT's projects (examples are MATCH, NETLogo Educational Site).

\subsubsection{Current problems}

Currently, DIT and TTC do not have the capacity (technical, human, organisational and financial) to offer this kind of development to a vast majority of teachers. To go to a large-scale implementation, the above principles need to be made operational, a relevant methodology has to be developed to support the adopters of the framework. We work mostly with informatics and ICT teachers (this is a speciality of our educational system). Recently primary teachers were also addressed. All subject teachers at secondary school level should be involved in teacher development as well.

Another serious obstacle to building ICT school cultures is the low level of technological infrastructure in most schools. Also the low social and financial esteem of teachers is inadequate to the effort expected from the teachers.

\section{EXAMPLES FROM PRACTICE}

One specific feature of our approach is that the teacher development processes are initiated in a university environment in which research, 
development and teaching activities are closely interrelated. This creates added-value opportunities and experiences for the participating teachers.

\subsection{General examples}

\section{Curriculum development}

Teams of researchers and teachers were involved in the development of curricula for "Integration of ICT in primary school", "Informatics in Logo style", "Internet for beginners", "Internet for advanced". A set of accompanying materials and services is under development around each curriculum: workshops, teacher manuals, software, online resources.

\section{The Project "Learning by Developing"}

This project was initiated in the frames of the program "School initiative of IBM for Bulgaria". The "learning by developing" paradigm (Blaho \& Kalas, 1998) and Comenius Logo, an attractive and sophisticated environment with much conceptual and operational power, were employed to involve teachers and students in attractive and meaningful activities using ICT. The goal is to teach and learn better and to strengthen the creative spirit in using technology in our schools. We use LOGO because it enables children to deal with real ideas. It is a tool for carrying out engaging projects. Comenius Logo gives the possibility to create interactive applications (microworlds) in different subject areas. Teachers can tune existing microworlds to their classroom needs and/or build microworlds on their own.

The target group involved initially 16 schools. Gradually more schools and individuals joined. An integrated approach was used to spread Logo ideas and tools across the educational community and helping teachers integrate them in schools: the software was adapted to the Bulgarian language, Bulgarian online help was developed, and a whole range of reference, teaching and learning materials (lessons, problems, projects, and microworlds) was produced. In all these teachers were involved. In this sense the project is a good example for initiating and supporting educational innovations (Fullan, 1994). A "web" of Logo professionals who support each other and collaborate effectively was built.

\section{WWW support for teachers}

Maintaining educational websites does not only save time and help reach more users. Feedback from users is facilitated, two-way communication channel and mutual collaboration can be established. A positive effect is, that offering meaningful material and helpful interactions to teachers in such a way, they get used to using Internet for educational resources and motivated to make their own Web developments. One inconvenience is that 
educational Web sites need frequent updates and constant maintenance. Another aspect of websupport to teachers is the opportunity for tele-learning. A majority of online courses is already available. Teachers need guidance and some kind of brokerage service to be able to orient in it.

VALUE: A Virtual Almanac for Logo Users and Educators.

VALUE (the Virtual Almanac for Logo Users and Educators (Nikolova, 1997) was created to support the implementation of the project "Learning by Developing". The Web was used as a supplementary channel for reaching teachers, delivering materials to them, getting feedback and establishing collaboration. A rich collection of developed materials is uploaded to the site, communication and discussion are embedded (Conference Room), announcement (Current Events), building virtual Logo community (Guest Book). For easier orientation a site map is developed (see figure 1). Teachers contribute to the further development of VALUE (many of the resources there have been developed by our "change agents"). Many teachers benefit from VALUE, but the vast majority of teachers still do not have the habit and/or technological infrastructure to use virtual support like this. New culture has to be developed in this respect.

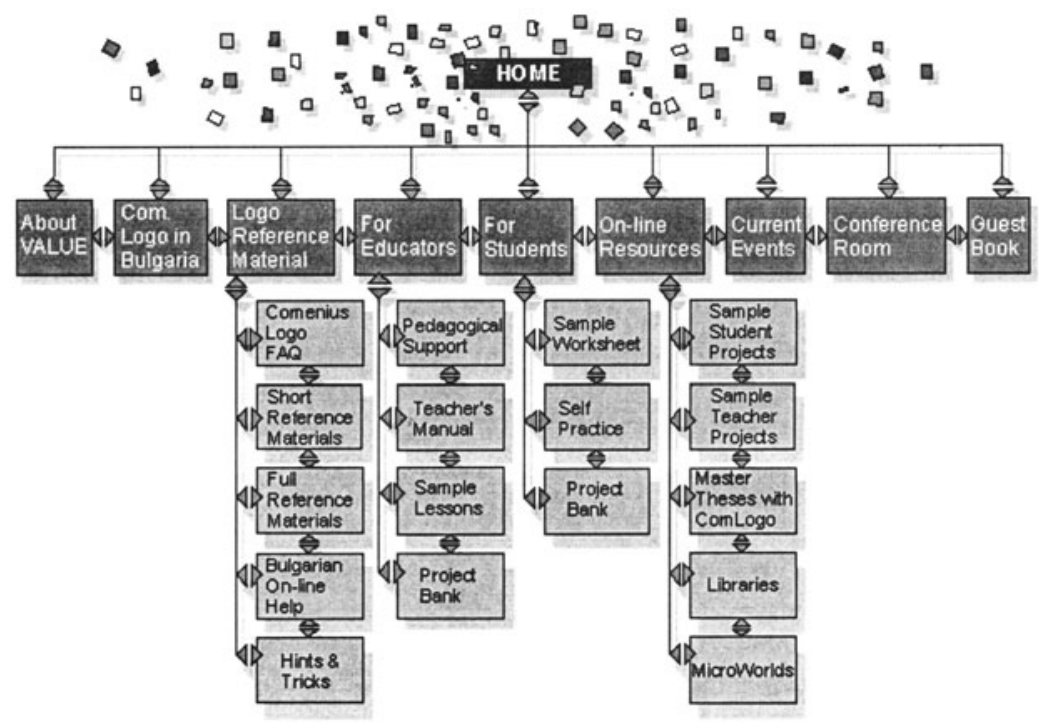

Figure 1. Sitemap of VALUE

NETLogo Web course for Teachers

Within the NETLogo project (Sampson et al, 1998) an online course for teachers (figure 2) is being developed collaboratively by a Hungarian and a Bulgarian team. Teachers are involved at different levels in this initiative. 
GEOMLAND: Laboratory for Mathematics Explorations in Logo Style GEOMLAND (Sendov \& Sendova, 1997) is a powerful Logo style learning environment for mathematics explorations, developed at ECSL, the Department's predecessor. The system is used in teacher training and in secondary schools. A recently developed Web site (Figure 3) provides teachers with the software, research and methodology papers, demonstrations and examples for school use, contact with the authors.

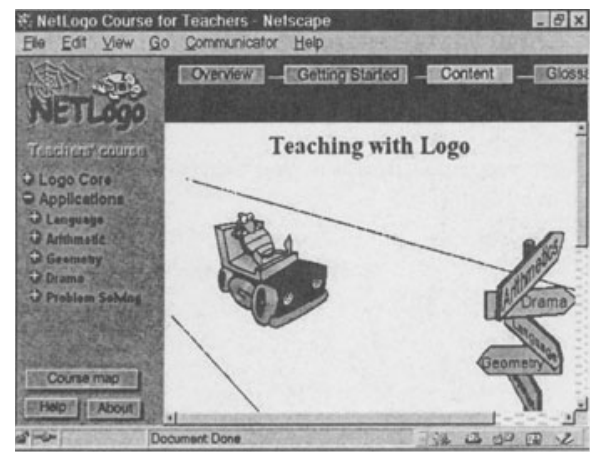

Figure 2: NetLogo Web Course for Teachers

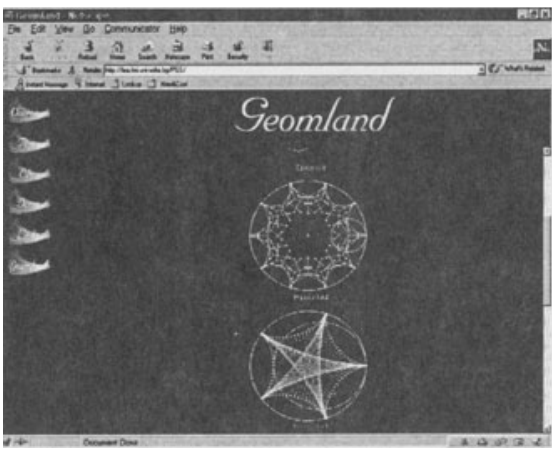

Figure 3: A Geomland Web page

\section{School Resource Bank: A Subject-Oriented Web Catalog}

This is a useful collection of annotated online educational resources to ease teachers in finding online subject-oriented materials. It was developed by a master student in cooperation with teachers. The site was offered to the Bulgarian I*EARN section for use by schools with Internet access.

\section{MATCH: A Multimedia Authoring Tool for Children}

In this recent European project (Triantafillou et al, 1997), where DIT collaborated with partners form Slovakia, Hungary, Holland, UK and Greece, an environment for multimedia authoring for children, MATCH, was developed. The system employs the constructionist learning philosophy and supports creative thinking and expression by means of multimedia technologies. We use multimedia authoring for children, to provoke children's thinking, imagination, expression and active learning; to enable them to taste the process of creating multimedia and to personalise the basic concepts of the multimedia world surrounding them; to create a context, in which each child can participate in an enjoyable collaborative activity with what she or he is talented for. 


\subsection{APPLICATIONS DEVELOPED IN BULGARIA}

Several applications were developed with MATCH which demonstrate the power of the environment and served as system testbeds.

\section{Multimedia Screen Cards}

The application (figure 4) faces children with most popular European traditions and festivals related to children. A multimedia screen card is a moving, speaking, singing card, the child can play with, print, modify, export into a Web page. Sample cards for different occasions were developed and built into a consistent Screen Card World.

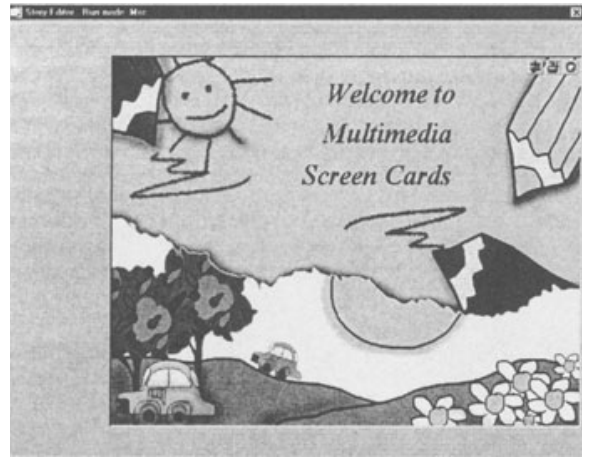

Figure 4: Entry to the Screen Card World

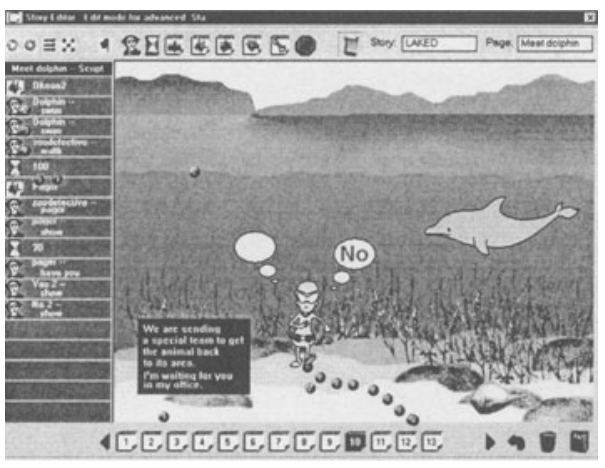

Figure 5: "Save the Animals" game

Save the Animals

This application (figure 5) illustrates the possibility to design multimedia games with MATCH. It is a story where the child plays the role of a Zoo Detective, trying to help an animal in danger. The application has a modular structure and allows modification and extension by teachers and students.

\section{Children's Projects}

While testing the system and applications in school, children made their own production with MATCH - individual screen cards and class projects "Meet our class" and "Class album". This work kept both children and teachers very much involved and provoked learning about multimedia technologies and numerous ideas for multimedia projects. 


\section{TEACHER INVOLVEMENT}

Teachers (our "change agents") were involved in the development of MATCH applications and in testing the system and the applications in schools. MATCH was used in teacher training to illustrate "learning by developing" paradigm and ideas for using multimedia for creative expression. In the near future it will be made available to more teachers for use in their classrooms. These teachers will contribute to the production of the Bulgarian version of the system and the applications.

\subsection{Implications for future teacher education}

It is inevitable that in the near future all teachers will have to cope with UCT in one way or another (Collis, Nikolova \& Martcheva, 1995). It is important that they have a deeper insight in the ways ICT could help learning. When featuring the direction, in which he would like to see the educational system going (in his academic speech, "The Future of Learning", at the Ceremony for awarding him with Dr. Honoris Causa of Sofia University, in August, 1999), Seymour Papert talked about Constructionism as a theoretical foundation for education using a more project-based approach. He pointed out, that currently many teachers have difficulties embedding powerful ideas in projects and/or recognising powerful ideas embedded in existing projects. He felt the need for developing epistemologies of powerful ideas to be explored in computationally rich environments. To cope with the tendency for globalisation of education, future teacher education has to take into account the explosion of tele-learning. A global electronic brokerage system would ease the orientation of teachers in the global learning space. The time has come for teachers using technology to become an actively learning and collaborating professional society. Internet provides good opportunities to build virtual professional communities.

\section{CONCLUSIONS}

The educational research is a longitudinal process. It is too early to say if the approach presented in this paper is a good solution to the problem of teacher development or not. The university setting addressed in the paper is one of the main places in Bulgaria where secondary school teachers in informatics and IT are prepared. Nevertheless, there is still a way to go before the approach presented in the paper can be considered a large-scale example. In this respect DIT and TTC act as "change agent" themselves. 
Every opportunity is used to bring our vision and experiences to the professional community. The teachers, "change agents" are our advocates.

\section{REFERENCES}

Blaho, A. and Kalas, I. (1998) Learning by Developing with Comenius Logo, Longman Logotron, London.

Collis B., Nikolova I., and Marcheva, K. (Eds.) (1995) Information Technologies in Teacher Education: Issues and Experiences for countries in transition, UNESCO, Paris.

Eshkenazi, Assenova, Michnev, Nikolova, and Lakyurski (1998) National Strategy for integration of ICT in the Bulgarian Secondary Schools, Ministry of Education, Sofia

Fullan, M. (1994) The New Meaning of Educational Change, Cassel.

Nikolova, I. (1999) Teacher Training in Informatics and ICT, In Peicheva, R, (Ed.) New Approaches of ICT in Teacher Training, Phare -TEMPUS (in Bulgarian)

Nikolova, I. (1997) Towards VALUE - A Virtual Almanac for Logo Users and Educators, Proceedings, Eurologo'97: Learning and exploring with Logo, Budapest, p. 240-248. http://iea.fmi.uni-sofia.bg/value/

Papert, S. (1999) Constructionism: Putting Logo into Pratice, in Nikolov, Sendova, Nikolova, Derzhanski (Eds.) Proceedings of the Seventh European Logo Conference EUROLOGO'99, Sofia.

Sampson et al (1999) NETLogo: The European Educational Interactive Site, in Nikolov, Sendova, Nikolova, Derzhanski (Eds.), Proceedings of the Seventh European Logo Conference EUROLOGO'99, Sofia, Bulgaria.

Sendov, B. and Sendova, E. (1997) Tuning a Logo-like learning environment to a knowledge domain, in Proceedings, Eurologo'97: Learning and exploring with Logo, Budapest

Triantafilou, S., Pixton, J., Kallenbach, K., Kalas, I., Turcsányi-Szabó, M., Pintelas, P., and Nikolova, I. (1997) MATCh: a Multimedia Authoring environment for Children, Eurologo'97: Learning and exploring with Logo p. 80-84

\section{BIOGRAPHY}

Iliana Nikolova is a chief assistant professor at the Department of Information Technologies, Faculty of Mathematics and Informatics, University of Sofia, Bulgaria. She has been working for more than 12 years in the following areas: applications of ICT in teaching and learning, teacher development in ICT, educational multimedia, and tele-learning. Her recent research, development and teaching activities involve methodology and tools for Web-based course design, multimedia authoring and applications for children, integration of Logo-style computer environments in schools. She has a M.Sc. in Computer Science (University of Sofia, Bulgaria) and a M.Sc. in Educational and Training Systems Design (University of Twente, The Netherlands). She is a member of IFIP Working Group 3.6. 